\title{
The Analysis of Activity of the Teacher of Engineering Geometry in the Conditions of the Digital Educational Environment
}

\author{
Konstantin Nosov ${ }^{1}$ and Lubov' Tarasova $^{1}$ \\ ${ }^{1}$ Perm National Research Polytechnic University, Komsomolsky prospekt, 29, Perm, 614990, Russia
}

\begin{abstract}
In article some aspects of activity of the teacher of engineering geometry in the conditions of remote work in the digital educational environment are considered. On the example of one of stages of work of the teacher of engineering geometry - check of the individual graphic tasks performed by students, the arising problems connected with "digitalization" of the geometricgraphic training in technical college are discussed. Data on the sequences of actions at the organization of "classical" process of training and training in the digital educational environment are compared and examples of algorithms of actions in the conditions of the digital educational environment are given. Also, between these two processes significant differences in the methodical and organizational formats connected first of all with differences in submission of information and financially technical support of these processes are detected. And in connection with a significant change in information and material content of discipline an engineering geometry the conclusion about the shift of priorities in acquisition by teachers of engineering geometry of necessary competences is drawn. On the example of the analysis of expenses of working hours and material inputs on technical support, the process of verification of individual graphic tasks, positive and negative sides of digitalization of the geometric-graphic training in technical college are considered.
\end{abstract}

\section{Keywords}

education digitalization, digital educational environment, geometric-graphic training, engineering geometry, individual graphic tasks, work of the teacher

\section{Introduction}

Modern information technologies make changes to all spheres of human activity, including also teaching. Implementation of the digital educational environment (DEE) in the higher technical education provides high-quality supply of the studied material and reduction of time for its assimilation [1]. But, according to authors, by consideration of the matter only by results, stays many "reefs" connected directly with work of the teacher "behind scenes".

Traditionally the geometric-graphic training (GGP) at technical institutes provide two disciplines: descriptive geometry and engineering schedule. Transformation of separate sections of discipline to the general under the name - the engineering geometry (EG) became trend of the last years. It is connected, including, with the escalating and combining role of computer technologies in problem solving of both descriptive geometry, and engineering graphics [2].

When training in the classical way, classroom - all requirements to performance of work, their registration and order of delivery are already registered in various educational and methodical literature and are stipulated by the teacher at the initial stage of preparation, according to already established practice. "Sudden" transition to remote format of training because of emergency situation (COVID-19) has shown that there are rather extensive gaps in the general methodology of teaching EG.

After end of remote format of training there was transition not back to classroom, and to some mixed format - practical and laboratory works are carried out in audiences, and reception from students of

GraphiCon 2021: 31st International Conference on Computer Graphics and Vision, September 27-30, 2021, Nizhny Novgorod, Russia EMAIL: designcon@ya.ru (K. Nosov); liebe_perm@mail.ru (L. Tarasova)

ORCID: 0000-0002-3265-9091 (K. Nosov); 0000-0003-1819-4723 (L. Tarasova)

(c) (i) 2021 Copyright for this paper by its authors.

Use permitted under Creative Commons License Attribution 4.0 International (CC BY 4.0).

CEUR Workshop Proceedings (CEUR-WS.org) 
individual graphic tasks (graphic works) mostly became remote [3]. On the example of one of such stages of work of the teacher of engineering geometry further we will consider the arising difficulties and ways of their decision.

In this article the problem of copying (plagiarism) is not considered by students of graphic works or performance by third-party performers as this problem demands separate research. It would only be desirable to note that according to authors to solve it only in DDE conditions rather difficult, without direct control of the teacher of step-by-step performance of tasks or introduction of intermediate control tasks directly on each graphic work of students.

\section{Aspects of formalization of activity of the teacher of EG in the conditions of DEE}

At traditional form of education all graphic works performed on engineering geometry were accepted by the teacher only on paper - irrespective of performance format, manually or on the personal computer (PC). In DEE of options has ideas of information carriers the bigger variety limited only to PC opportunities to display and availability of the corresponding software is considerable.

In Figure 1 the simplified sequence of actions of the teacher of EG in the course of interaction with the student is given to DEE which are directly concerning only individual graphic tasks.

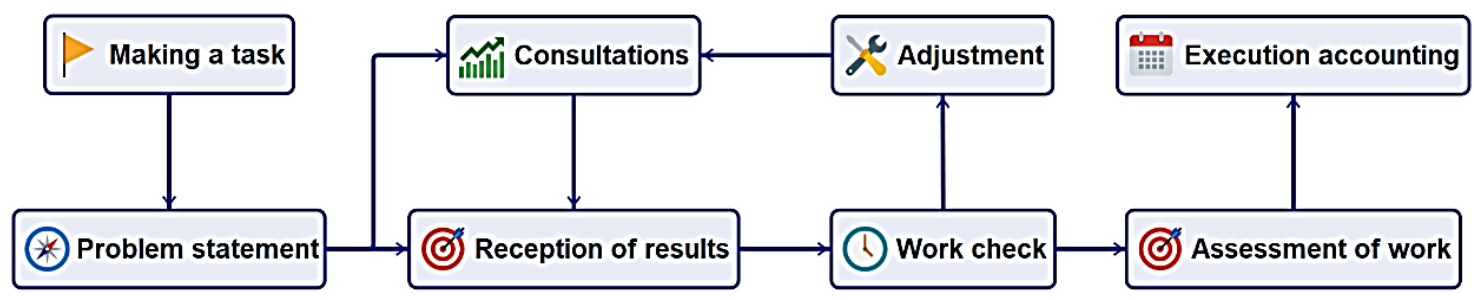

Figure 1: Operating procedure of the teacher of EG with graphic works in DEE

On each of stages there is certain type of activity of the teacher:

- Delivery of task. Delivery of package of the tasks distributed on discipline subjects by options.

- Problem statement. Bringing to students of order of performance of task, requirements to registration and other formal requirements.

- Reception of task. Directly process of receiving by the teacher of the information carrier containing either part, or all task.

- Check of task. Directly the process of verification of task on the information carrier intellectual work of the teacher.

- Adjustment. Use of results of check for finishing them to the student - introduction of graphic and text marks directly on the information carrier.

- Consultation. Assistance to the student in case of misunderstanding from its party of separate provisions of result of adjustment or problem statement.

- Offset of task. Direct reception of task on condition of compliance to its evaluation criteria.

- Performance accounting. In the absence of material object - the information carrier, is necessary high-quality accounting of all actions and results of work of the student.

At stage of check and adjustment professional competences of the teacher are directly applied. Besides competences of the subject of EG, competences of use of the computer equipment - the software and various computer peripherals have to be involved here. In Figure 2 the example of check of graphic work with use of the graphic tablet or the manipulator which considerably accelerates process of drawing graphic and test marks in the field of graphic work is given. 


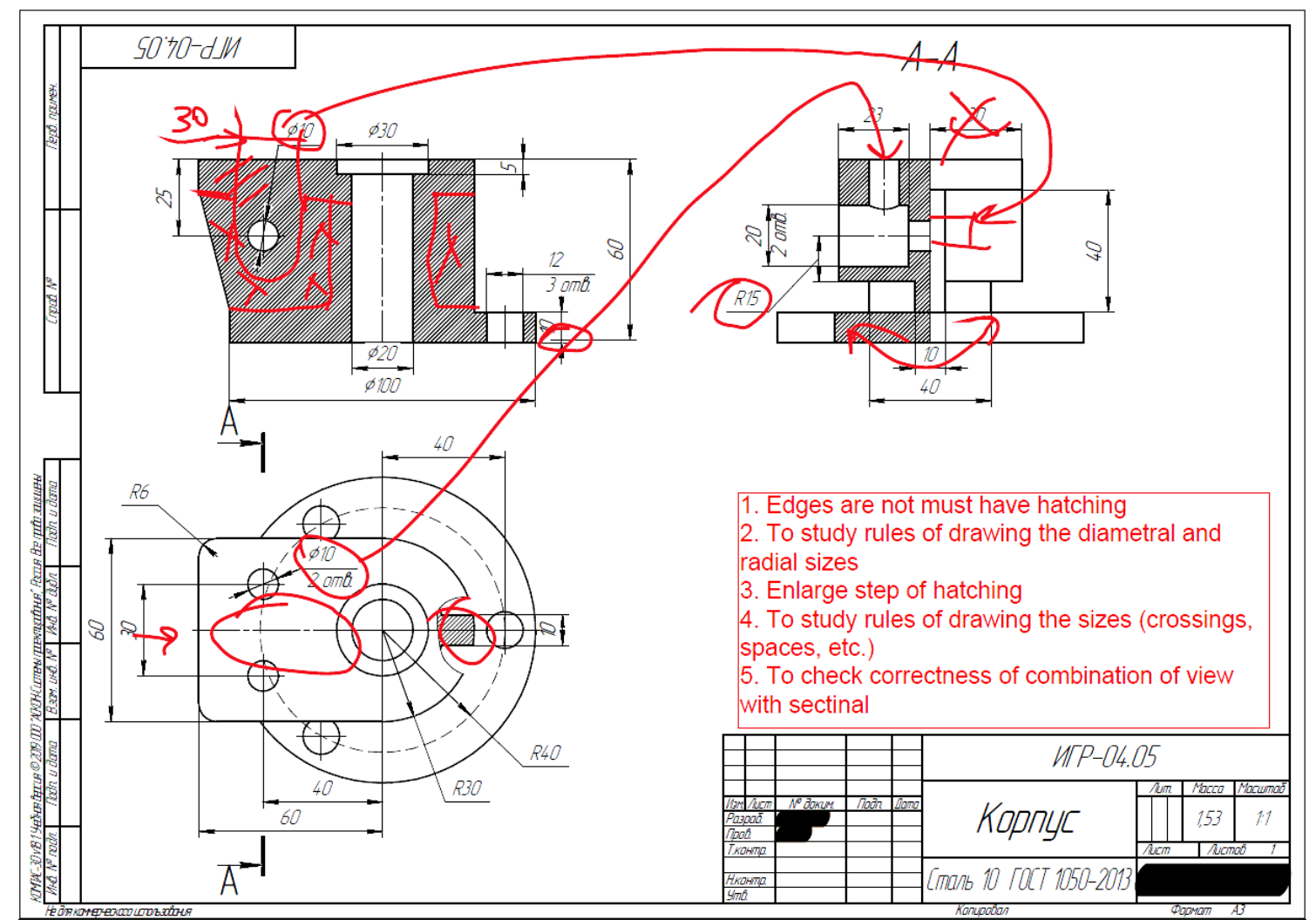

Figure 2: Example of commenting of graphic work as the teacher of EG in DEE

In Table 1 the approximate option of use of DEE technologies by the teacher is given in each of the above-stated stages. The last column in the table - the PC generalizing all software on the teacher's PC which is used only on it, without interaction with the student. For example, any CAD, editor of images or files of the PDF format. Thus, the stage of adjustment happens directly on the teacher's PC to use of various software.

Table 1

Example of use of DEE technologies at various stages of activity of the teacher of EG

\begin{tabular}{|c|c|c|c|c|c|c|}
\hline \multirow{2}{*}{$\begin{array}{l}\text { Name of stages } \\
\text { of work }\end{array}$} & \multicolumn{6}{|c|}{ The applied DEE technologies } \\
\hline & $\begin{array}{l}\text { Cloud } \\
\text { storage }\end{array}$ & $\begin{array}{l}\text { Website } \\
\text { DE }\end{array}$ & E-mail & Messenger & $\begin{array}{c}\text { Service of } \\
\text { videoconferences }\end{array}$ & PC \\
\hline Delivery of task & + & + & + & + & & \\
\hline $\begin{array}{l}\text { Problem } \\
\text { statement }\end{array}$ & + & + & + & + & + & \\
\hline Consultation & & + & + & + & + & \\
\hline Reception of task & + & + & + & + & & \\
\hline $\begin{array}{c}\text { Check of task } \\
\text { Adjustment }\end{array}$ & & + & & & & $\begin{array}{l}+ \\
+\end{array}$ \\
\hline Offset of task & + & + & & & + & + \\
\hline $\begin{array}{l}\text { Performance } \\
\text { accounting }\end{array}$ & + & + & & & & + \\
\hline
\end{tabular}

Any professional activity means availability of certain competences, but in set of cases, at emergence of the situations which are not provided by administrative documentation and methodical literature, sometimes it is difficult to define independently what of competences is necessary at present. As professionalism is developed over the year's practices or with timely skills development $[4,5]$. 
For example, we will consider - what competences are necessary for check and reception of graphic works, at traditional form of education, on papers:

- Delivery of task. Ability to give paper with the description of task provided that tasks are created in advance.

- Problem statement. Ability to tell or instruct orally on reading of order of performance of task, requirements to registration and other formal requirements.

- Reception of task. Ability to pick up the drawing and pencil for marks.

- Check of task. Here the whole complex of competences as this process occupies up to $90 \%$ of all operating time with task - such as knowledge of descriptive geometry, ESKD and many other is necessary.

- Adjustment. Ability to formulate divergences between the checked result and the right decision in verbal, text and graphic form.

- Consultation. Ability to understand and formulate divergences between knowledge of the student and the "correct" knowledge.

- Offset of task. Ability to make the decision on "objective" assessment, considering the whole range of factors, such as - quality of performance of task, the number of approaches, tendency to improvement of quality of performance of task from the moment of the beginning of performance, taking into account the number of consultations, etc.

- Performance accounting. Ability to register mark about performance of task or card of accounting of progress.

In turn check of graphic works in DEE means use various software and also, perhaps, computer peripherals and gadgets. Respectively the corresponding competences are necessary for work with certain type of software if earlier did not face it. The same and with peripheral devices which are not among obligatory at traditional form of education.

Such competences in itself do not appear - for their forming it is necessary to prepare in advance, to improve skills - to be trained by the third-party expert or to be engaged in self-education. In the conditions of "emergency" transition to remote operating mode the teachers often had no time to be prepared in due measure that has led to the fact that everyone developed the technique of work and the sequence of actions. Each teacher independently determined need for auxiliary software of computer peripherals, etc.

The approximate scheme of actions of the teacher of EG is provided on Figure $\mathbf{3}$ (on the basis of poll). On the scheme not the most optimal variant assuming that at the time of transition to distance learning requirements for order of representation of tasks have not been in advance created - in initial format or preservation in format convenient for viewing and fast commenting when performing on the PC is shown or in format of photo and the scanned image in case of performance manually on paper.

As a result of development of discipline engineering geometry the student has to know: State standards of ESKD, regarding rules of performance and execution of design documentation (drawings and schemes) to own methods of modeling of details and assembly units in a CAD and to be able to represent a form of the projected objects and their relative positioning in space [6]. In this connection preservation or ensuring acceptable presentation and informational content, necessary for formation and fixing at the student of the corresponding competences becomes the main problem of information transfer from the teacher to the student.

For example, on the basis of one of trajectory options, according to Figure 3, it is possible to make the software approximate list which is minimum necessary for work in DEE. The software list is provided in Table 2 [3]: 


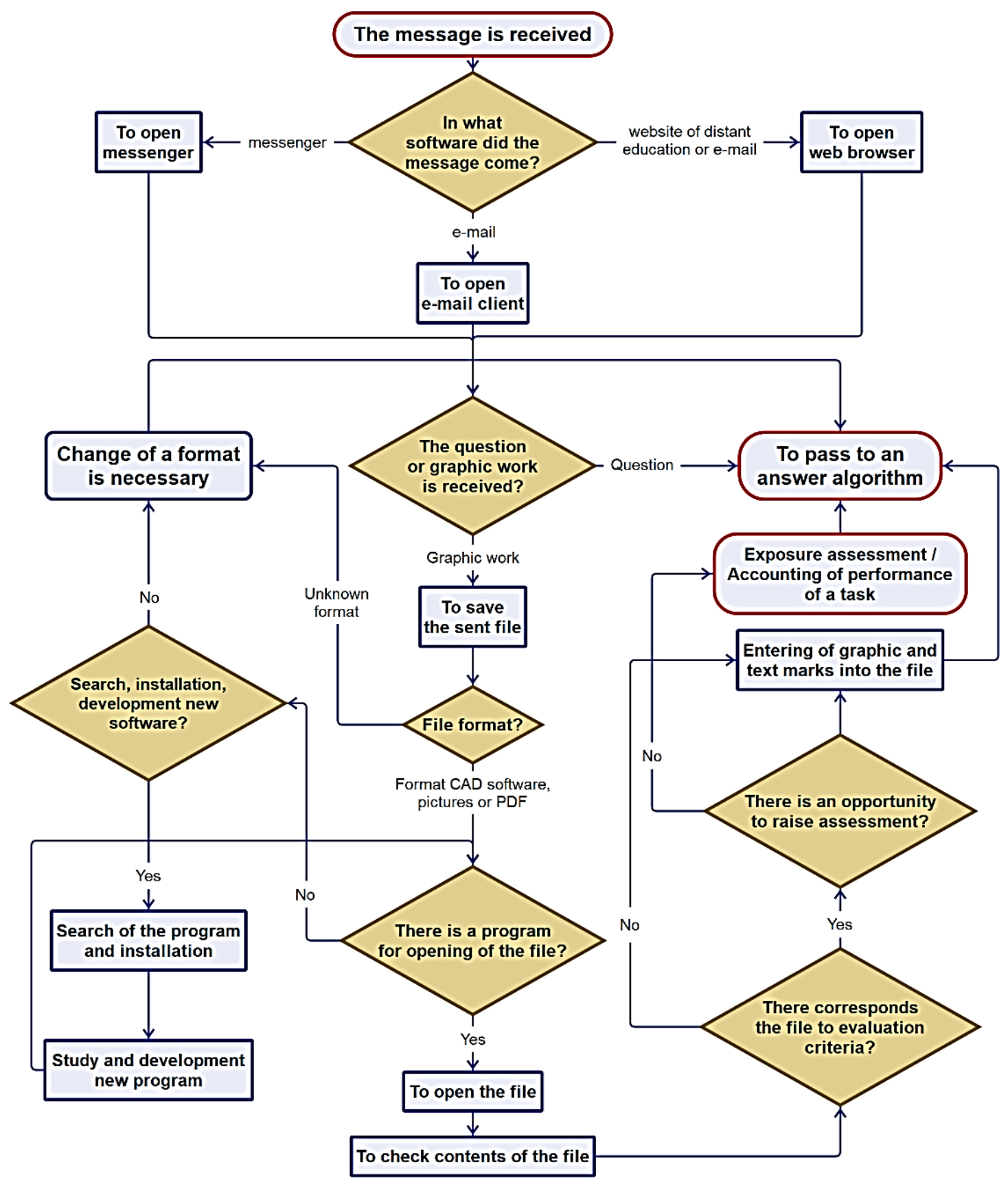

Figure 3: The sequence of check of graphic works in DEE if initial conditions of their registration and granting are not defined

It is also necessary to note that not all rather functional software is free. That is, it can turn out so that one proprietary program blocks all range of tasks of check, editing and to preservation of works, and for just the same work among free analogs it is necessary to use 2 or 3 programs. What considerably increases the number of transitions and as a result time for performance of professional duties. Expenses on the proprietary software are, usually, born by the teacher that is connected, first of all, with lack of the general regulations of performance of professional duties in the conditions of DEE. 
Table 2

The software approximate list necessary for the teacher of IS in DEE

\begin{tabular}{|c|c|c|}
\hline № & Types of software & Application in DEE \\
\hline 1 & $\begin{array}{l}\text { The website of distance education } \\
\text { (under the authority of the } \\
\text { educational organization) }\end{array}$ & $\begin{array}{l}\text { Placement of tasks and receiving, through the built- } \\
\text { in services of the website, files of graphic tasks. } \\
\text { Preservation of history of educational trajectory of } \\
\text { the student }\end{array}$ \\
\hline 2 & $\begin{array}{l}\text { Online services of cloud storages } \\
\text { of data or clients for access to } \\
\text { them }\end{array}$ & $\begin{array}{l}\text { Placement of files of tasks and other materials on } \\
\text { discipline }\end{array}$ \\
\hline 3 & $\begin{array}{l}\text { Services or software for } \\
\text { videoconferences }\end{array}$ & $\begin{array}{c}\text { Carrying out videoconferences with students for } \\
\text { consultation and reception of the performed tasks in } \\
\text { the form of interview }\end{array}$ \\
\hline 4 & $\begin{array}{l}\text { Online services or the software on } \\
\text { work with format of the PDF files }\end{array}$ & $\begin{array}{l}\text { Opening, editing and commenting of files of graphic } \\
\text { tasks in the PDF format }\end{array}$ \\
\hline 5 & Web browser & Ensuring access to the websites of online services \\
\hline 6 & $\begin{array}{l}\text { Software of creation and editing } \\
\text { screenshots of the screen }\end{array}$ & $\begin{array}{c}\text { Creation and editing screenshots with possibility of } \\
\text { commenting of elements of the image of graphic } \\
\text { tasks }\end{array}$ \\
\hline 7 & The software for viewing images & Viewing and simple editing images \\
\hline 8 & $\begin{array}{c}\text { Online services or software for } \\
\text { creation, editing and placement of } \\
\text { media content }\end{array}$ & $\begin{array}{c}\text { Creation and editing educational media content and } \\
\text { organization of access to it }\end{array}$ \\
\hline 9 & $\begin{array}{l}\text { Software for opening of the CAD } \\
\text { files }\end{array}$ & $\begin{array}{l}\text { Opening of tasks in initial format and their } \\
\text { transformations to other formats }\end{array}$ \\
\hline 10 & $\begin{array}{l}\text { Software for receiving and } \\
\text { sending e-mail (e-mail clients) }\end{array}$ & $\begin{array}{l}\text { Obtaining files of graphic works and their } \\
\text { preservation on the personal computer with the } \\
\text { subsequent sending their checked versions }\end{array}$ \\
\hline 11 & $\begin{array}{l}\text { Software for exchange of fast } \\
\text { messages (messengers) }\end{array}$ & $\begin{array}{l}\text { Organization of operational consultations and } \\
\text { placement of announcements }\end{array}$ \\
\hline 12 & $\begin{array}{c}\text { Software for movement and } \\
\text { accounting of files and actions on } \\
\text { the personal computer } \\
\text { (databases, text editors, file } \\
\text { managers, etc.) }\end{array}$ & $\begin{array}{c}\text { Preservation and accounting of file history of } \\
\text { educational trajectory of the student }\end{array}$ \\
\hline
\end{tabular}

\section{Optimization of activity of the teacher of IS at stage of check of graphic works}

Educational process is process bilateral, respectively implementation of DEE has concerned both parties of process - teachers and students. In Table 3 we will compare schemes of work of the teacher of EG in conditions:

1. Classical process of training at which all graphic works are accepted on paper.

2. Process of training after implementation of DEE at which all graphic works are accepted in digital form. 
Table 3

Comparison of operation algorithms of the teacher of EG in classical option and in DEE

\begin{tabular}{|c|c|c|c|c|}
\hline \multirow[t]{2}{*}{ № } & \multicolumn{2}{|c|}{ Classical } & \multicolumn{2}{|l|}{ DEE } \\
\hline & Work stage & $\begin{array}{l}\text { Run time, on the } \\
\text { average }\end{array}$ & Work stage & $\begin{array}{c}\text { Run time, on the } \\
\text { average }\end{array}$ \\
\hline 1 & $\begin{array}{l}\text { Working method from } \\
\text { the student }\end{array}$ & 1 minute & Receiving/saving file & 2 minutes \\
\hline 2 & Work check & 3 minutes & $\begin{array}{l}\text { Opening of the file in } \\
\text { corresponding software }\end{array}$ & 2 minutes \\
\hline 3 & $\begin{array}{c}\text { Drawing graphic/test } \\
\text { marks }\end{array}$ & 5 minutes & Work check & 3 minutes \\
\hline 4 & & & Drawing graphic marks & 7 minutes \\
\hline 5 & & & Drawing text marks & 3 minutes \\
\hline 6 & & & $\begin{array}{l}\text { Saving the file with } \\
\text { marks }\end{array}$ & 1 minute \\
\hline 7 & Consultation (verbally) & 2 minutes & $\begin{array}{l}\text { Forming of the message } \\
\text { to the student in } \\
\text { corresponding software }\end{array}$ & 1 minute \\
\hline 8 & $\begin{array}{c}\text { Work transfer to the } \\
\text { student }\end{array}$ & 10 seconds & $\begin{array}{l}\text { Writing of the message } \\
\text { and attachment of the } \\
\text { file }\end{array}$ & 2 minutes \\
\hline
\end{tabular}

In the table options with expenses of time for actions of the teacher in DEE, out of regular regulations which are not just in classical educational process are not considered:

1. When there is need for opening in addition software or connections of any peripheral device (graphic the tablet, the manipulator, etc.).

2. At errors of opening or saving files, including if necessary, to keep in other format with support of graphic and text marks.

3. Delays in work the operation of the PC connected directly with speed.

In the conditions of classroom, resident instruction the teachers perform approximately identical functions just due to the general functionality and exchange of experience in real time. In the conditions of DEE each teacher takes the separate workplace most often equipped on sole discretion and owing to own competences of modern technologies. Someone performs work behind one small laptop or even the tablet, and someone works behind two and bigger monitors with use of the graphic tablets and other devices simplifying work with graphic information.

Figure 4 is presented on example one of options of algorithm of actions of the teacher of EG provided that all requirements to execution of files of graphic works and all algorithm of actions for students are registered at the initial stage of educational process in DEE. 


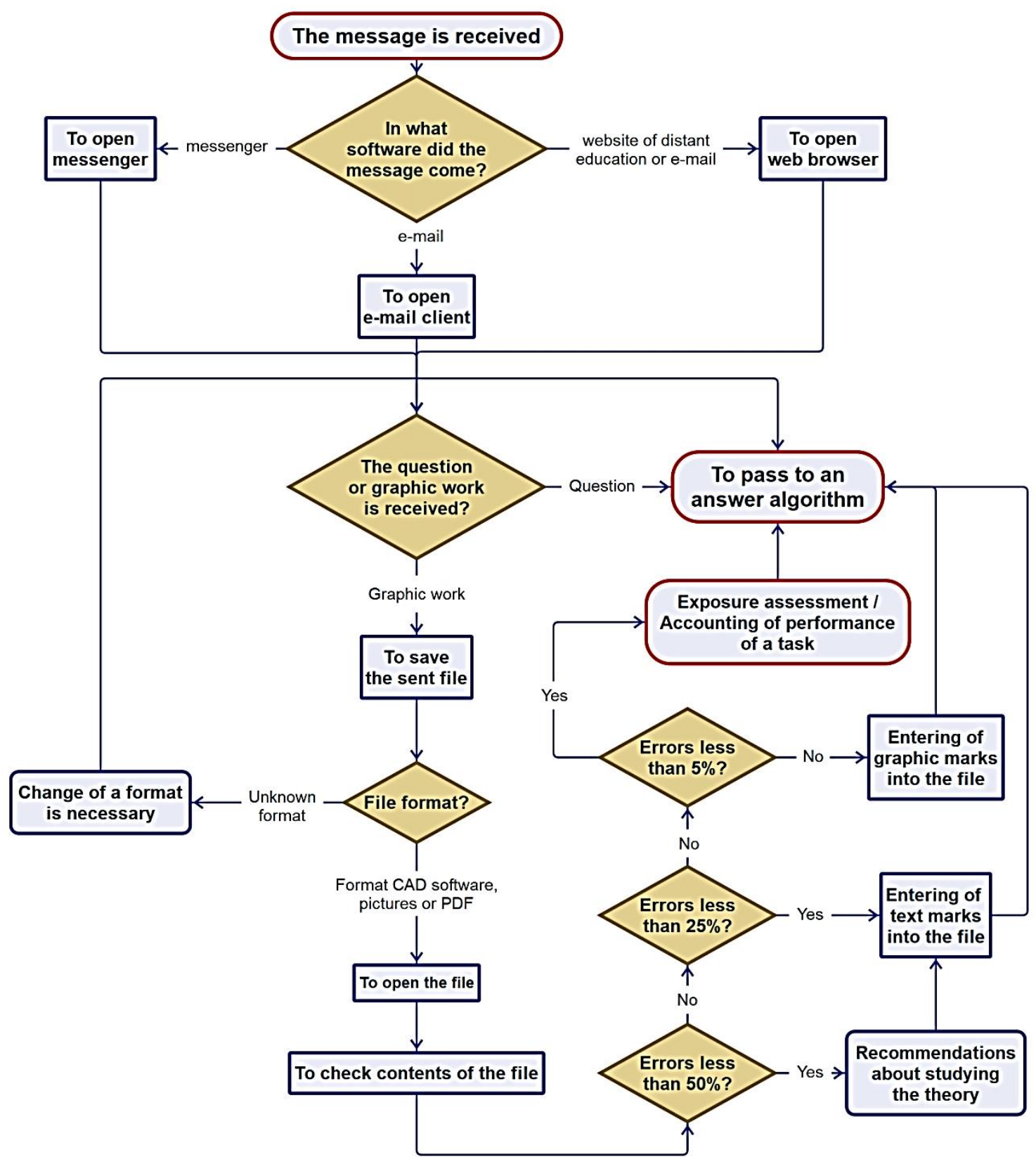

Figure 4: The sequence of check of graphic works in DEE if initial conditions of their registration and granting are defined

\section{Conclusions}

It is clear, that in the conditions of uncertainty at the moment, owing to various reasons, there was mixture of two approaches that in turn has considerably increased labor input of work of the teacher of EG due to complication of algorithm of actions. The solution of problems of copying of graphic works as students will lead to bigger increase of labor input. That is., check of theoretical knowledge in the course of the teacher's interview with the student, even in videoconference format, does not have alternative yet.

If accurately to define requirements to the provided files (to provide additional training) and to the used software, then the operation algorithm of the teacher of EG considerably will become simpler. Including the quantity of mistakes in the files received from students will decrease. I.e., proceeding 
from the aforesaid it is possible with confidence, to tell that in addition to the "digitized" classical training methodical materials or even the modern presentations and videos stating material "in a new way" need to reconsider, update and complement also such materials with new and necessary information. Such, as - recommended the software (freeware is desirable) and formats of files, including algorithms of actions for work with its software and formats of files. All above speaks about need for significant changes in requirements to registration of educational and methodical literature and technique of teaching EG. It is also necessary to consider at the level of management of higher education institution modification of regulations of work of the teacher of DEE, taking into account the needs for acquisition of the necessary software and computer peripherals.

Use of universal bilateral online service, with possibility of opening of various graphic formats of files, drawings on them graphic and text marks with the subsequent preservation, in real time would be the ideal decision, according to authors. Further development of such service can become implementation of neural network which eventually, studying at actions of the teacher, could if not to replace it, but to become the valuable assistant, considerably having increased labor productivity.

\section{References}

[1] I. Stolbova, K. Nosov, About Innovation Practice Within Geometric-Graphic Training, Graphicon 2020, Computer Graphics and Machine Vision, Proceedings of the 30th International Conference on Computer Graphics and Machine Vision, Saint Petersburg, 2020. doi: 10.51130/graphicon2020-2-4-33.

[2] L.S Sokolova, Engineering Geometry as a New Subject of Geometrical Graphics Training for Higher Technical Educational Institutions, Engineering Magazine: Science and Innovations 3 (2014). (In Russian).

[3] B.P. Deaconov, B.M. Igoshev, New roles of an educator in contemporary e-educational environment, Bulletin of the Chelyabinsk State Pedagogical University 5 (2014). (In Russian).

[4] G.A. Yarkova, M.A. Khamitova, About a Problem of Formation of Competence as Bases of Preparation for Professional Activity, Modern Problems of Science and Education 3 (2013). (In Russian).

[5] I.G. Borisenko, The Competence Approach in Teaching the Descriptive Geometry and Engineering Graphics, Bulletin of KRASGU 12 (2011). (In Russian).

[6] M.B. Talanova, Teaching Engineering and Computer Graphics, Baltic Humanitarian Magazine 1 (2015). (In Russian). 